\title{
Entre a rebeldia e a ingenuidade: representações sobre as juventudes em O que é isso, companheiro? e Batismo de Sangue
}

\author{
Danielle Parfentieff de Noronha ${ }^{2}$ \\ Universitat Autònoma de Barcelona
}

Resumo: Neste trabalho, analiso as representações sobre as juventudes do período correspondente à ditadura civil-militar brasileira (1964-1985) nas narrativas do cinema brasileiro contemporâneo, com o estudo dos filmes $O$ que é isso, companheiro? (Bruno Barreto, 1997) e Batismo de Sangue (Helvécio Ratton, 2007). A partir da disputa que envolve a memória desse período, busco desenvolver uma reflexão que leve em consideração a relação entre realidade e ficção existente em torno do tema, que pode criar, reforçar ou modificar o imaginário (social, coletivo) sobre quem foram aqueles jovens, e ainda atuar na construção de discursos imaginativos sobre a juventude do presente.

Palavras-chave: cinema, ditadura civil-militar, memória, juventudes, representação.

\footnotetext{
A primeira versão do presente trabalho foi publicada em: Congreso Internacional Ibercom, 2013, Santiago de Compostela. Libro de Actas XIII Congreso Internacional IBERCOM. Santiago de Compostela: AssIBERCOM / AGACOM, 2013. v. XIII.

2 Jornalista, mestre em Antropologia pela Universidade Federal de Sergipe - UFS e doutoranda em Medios, comunicación y cultura pela Universitat Autònoma de Barcelona - UAB.
} 


\section{Entre la rebeldía y la ingenuidad: representaciones sobre las juventudes en O que é isso, companheiro? y Batismo de Sangue}

Resumen: En este artículo, analizo las representaciones sobre las juventudes del período correspondiente a la dictadura civil-militar brasileña (1964-1985) en las narrativas de cine brasileño contemporáneo, con el estudio de las películas O que é isso, companheiro? (Bruno Barreto, 1997) y Batismo de Sangue (Helvécio Ratton, 2007). A partir de las disputas sobre la memoria de ese período, intento desarrollar una reflexión que considere la relación entre realidad y ficción existente en torno al tema, que puede criar, reforzar o cambiar el imaginario (social, colectivo) sobre quién fueron aquellos jóvenes, además de actuar en la construcción de discursos imaginativos sobre la juventud del presente.

Palabras-clave: cine, dictadura civil-militar, memoria, juventud, representación

\section{Between rebellion and ingenuity: representations of youth in O que é isso, companheiro? and Batismo de Sangue}

\footnotetext{
Abstract: In this paper, I analyze the representations about youth in Brazilian civil-military dictatorship period (1964-1985), from contemporary national cinema narratives, focusing on the films $O$ que é isso Companheiro? (Bruno Barreto, 1997) and Batismo de Sangue (Helvécio Ratton, 2007). From the dispute involving the memory of that period, I seek to develop a reflection considering the relations between reality and fiction existing around the theme, which can create, modify or reinforce the (social, collective) imaginary about who were that youth, and also influence the construction of today's youth imaginative discourses. youth

Keywords: cinema, civil-military dictatorship, memory, representation,
} 


\section{Introdução}

A construção da memória coletiva nacional relativa à ditadura civil-militar, instaurada no Brasil entre os anos de 1964 e 1985, está numa constante tensão entre as diferentes interpretações sobre o período, pelo fato de haver versões hegemônicas e outras versões menos evidenciadas, que reivindicam o direito de falar a "verdade"3 sobre esse passado. O relatório desenvolvido pela Comissão Nacional da Verdade 4 ampliou o espaço oficial para a difusão destas diferentes memórias e ainda mais o embate entre as versões. Porém, mesmo antes da instituição da comissão, outros meios eram utilizados como forma de dar visibilidade às memórias "silenciadas", que não encontravam espaço nos documentos ou em outros meios oficiais de veiculação. O cinema se tornou um campo importante para a manifestação destas diferentes representações e a produção cinematográfica brasileira, principalmente a partir dos anos 1990, acumulou um grande número de obras que trabalham com representações acerca deste tema.

Uma categoria importante desse passado que está em disputa no presente é a juventude e a sua participação na luta contra a ditadura. Em grande parte dos filmes que trabalham o período é possível ter contato com representações sobre esses jovens, sendo que, em muitas obras, a juventude aparece como protagonista. São ativados agentes que são representados e imaginados de diferentes formas: como heróis, rebeldes ou responsáveis pelo caos do passado. Os filmes disputam os modos com que as pessoas entendem o período e as juventudes que o vivenciaram, compartilhando uma forma de entender a nação, além de produzir ou reproduzir mitos relacionados com o que é ser jovem, no passado e no presente. Dessa forma, os filmes podem dar aos jovens de hoje (e à sociedade como um todo) uma indicação de um ideal de juventude brasileira. Lembro que essa categoria é muito utilizada para representar as variadas transformações políticas e culturais que ocorreram nos anos 1960 e 1970 em diversos lugares do mundo, em que o ano de 1968 é considerado uma data emblemática para debater a relação entre juventude, política e cultura.

No presente artigo busco refletir sobre as representações das juventudes do período ditatorial pelas narrativas contemporâneas do cinema brasileiro e as diferentes formas que atuam e estão em tensão pela construção da memória social sobre o período. Após um levantamento de cerca de 50 obras, os filmes escolhidos para análise foram $O$ que é isso, companheiro? (Bruno Barreto 1997) e Batismo de Sangue (Helvécio Ratton - 2007), pois foram percebidos em ambos os títulos grande parte das características utilizadas nos demais filmes para caracterizar a juventude. Além disso, as duas obras trazem diferentes pontos de vista em relação aos jovens e, grosso modo, estão em tensão pela

\footnotetext{
${ }^{3}$ Entendo a verdade como um campo político tenso, que se encontra em constante movimento e que não pode ser entendida como algo do passado que aguarda ser resgatado, mas algo que está em constante construção.

${ }^{4}$ Lei No 12.528 , de 18 de novembro de 2011. A comissão foi instalada oficialmente em 16 de maio de 2012 pela presidenta Dilma Rousseff, com objetivo de "efetivar o direito à memória e à verdade histórica e promover a reconciliação nacional”. A comissão entregou o relatório final em dezembro de 2014. Composto por 4.328 páginas, o documento consolida o trabalho da comissão, que contou com audiências públicas, depoimentos de militares e civis, e coleta de documentos sobre o período. Além disso, a comissão sugere 29 medidas, que se dividem em três tipos: institucionais, mudanças na lei ou na constituição e projetos para a continuidade das investigações e pesquisas. O relatório pode ser acessado em: http://www.cnv.gov.br/
} 
significação de quem eles foram, muitas vezes a partir de significados aparentemente naturalizados, com caráter discursivo. Os dois filmes têm em comum ainda o fato de serem baseados em livros biográficos: $O$ que é isso, companheiro? (1981), de Fernando Gabeira, e Batismo de Sangue (1982), de Frei Betto. Nesse sentido, os filmes foram inspirados em histórias consideradas reais, que trazem memórias de pessoas que viveram a juventude no período militar, a partir de uma ótica pós-ditatorial5, isto é, uma releitura sobre o passado $^{6}$, elaborada anos depois dos acontecimentos. As duas obras também contextualizaram as suas narrativas sobre um período próximo ao ano de 1968. São dois pontos de vista sobre o mesmo período de radicalização do autoritarismo e das perseguições políticas no país, com o advento do AI-57.

Este trabalho é resultado de um projeto maior desenvolvido para a minha dissertação de mestrado (DE NORONHA, 2013), na qual realizei uma etnografia fílmica das obras selecionadas, e traz alguns apontamentos dos resultados da pesquisa. Vale destacar que a intenção não é verificar a veracidade das histórias, como também não é apontar que não tenham ocorrido, já que o trabalho busca discorrer acerca das representações. Parte-se da ideia que o filme é uma narrativa mítica, no sentido que Barthes (2009) deu ao mito, isto é, como parte de um sistema de comunicação, que opera simbolicamente pela linguagem. Depois, do pressuposto que todo filme é um trabalho de ficção, uma representação, que inclui a mise-en-scène ${ }^{8}$ e os diversos processos de escolha $\mathrm{e}$ edição. Como linguagem, o cinema é uma ferramenta ideológica capaz de suscitar imaginários, reproduzir mitos e reformular memórias, individuais e coletivas9.

Como explicam Albert Chillón e Lluís Duch (2012), os movimentos míticos são grandes complexos simbólicos que colocam em movimento narrativa e culturalmente os vários recursos da faculdade imaginativa. Para García, Canul e López (2009), o mito como construção humana é resultado da necessidade de dar sentido a vida, o que perpassa o seu conteúdo simbólico, o convertendo num provedor de modelos de comportamento, que justifica a estrutura social ao atuar como linguagem através da qual se deve interpretá-lo. As condições conotativas e denotativas das narrações míticas possibilitam que elas se estendam para além do que se pode ver e de seu conteúdo simbólico para se formar em uma visão sobre a realidade, com um grupo de orientações que auxiliam as pessoas a entender as suas vidas e das demais pessoas. Os autores

\footnotetext{
${ }^{5}$ Os livros foram publicados antes do término da ditadura, em 1985, porém foram escritos após o encerramento do AI-5, em 1978, quando o Brasil começava a caminhar para um processo de redemocratização.

${ }^{6}$ É importante lembrar que os filmes são uma segunda releitura sobre o passado. A primeira foi realizada pelos autores dos livros em que os filmes foram baseados. A segunda é a dos diretores sobre como as narrativas dos livros, que dependem ainda de uma terceira leitura, realizada pelos espectadores, que podem ser as mais variadas, já que pontos de vista são resultados da relação entre obra e sujeito.

${ }^{7}$ O AI-5 foi promulgado em 13 de dezembro de 1968 com o objetivo de impedir o avanço "comunista" e preservar o interesse da "revolução", como os militares chamavam o golpe de 64. Foi considerado "o golpe dentro do golpe". A implementação do AI-5, dentre as mudanças que previa, deu plenos poderes ao governo, decretou recesso ao Congresso Nacional, às Assembleias Legislativas e às Câmaras de Vereadores; aumentou os mecanismos de censura a todos os meios de comunicação e arte e instaurou de vez a prática da tortura e a "caça aos comunistas". O fim AI-5 ocorreu em dezembro de 1978.

${ }^{8}$ Mise-en-scène significa literalmente "posto em cena". É utilizada no meio cinematográfico para representar a arte da encenação, daquilo que é montado e planejado para configurar a cena e torná-la "real".

${ }^{9}$ Sobre memória individual e memória coletiva, Halbwachs (1990: 72) acredita que há uma relação intrínseca, em que a memória individual é um ponto de vista da memória coletiva. As pessoas compartilham de uma memória comum porque se identificam com ela de alguma forma, do mesmo modo que "o funcionamento da memória individual não é possível sem esses instrumentos que são as palavras e as ideias, que o indivíduo não inventou, mas que toma emprestado de seu ambiente". Nesse sentido, "para que a nossa memória se aproveite da memória dos outros, não basta que estes nos apresentem seus testemunhos: também é preciso que ela não tenha deixado de concordar com as memórias deles e que existam muitos pontos de contato entre uma e outras para que a lembrança que nos fazem recordar venha a ser constituída sobre uma base comum”. (Halbwachs, 1990: 39).
} 
defendem que o mito estrutura e legitima ordens sociais, modos de vida, práticas e formas de expressar coesão e inserção social regulando a estrutura social, ética e moral das comunidades ${ }^{10}$. Nesse sentido, o tema deste artigo remete, em primeiro lugar, ao efeito de real, ideia que Roland Barthes (2004) desenvolveu para a literatura, mas que também está presente nas obras cinematográficas, que pode criar, reforçar ou modificar o imaginário nacional sobre quem foram esses jovens, além de reformular o discurso sobre a nação. Para Barthes, o "efeito de real" consiste nas estratégias utilizadas nas narrativas realistas para descrever ao leitor o ambiente proposto, que representam o "real" a partir de sentidos conotados e denotados, de tal modo que sejam apagados os resquícios da artificialidade e criada uma relação entre leitor e texto, a partir das referências do que o leitor entende por "realidade".

Em segundo lugar, aponta também à relação entre arte e vida que, a partir das ideias propostas pela antropologia interpretativa, possibilita a observação, análise e interpretação da arte como um importante artefato cultural, que "fala" muito da cultura da qual faz parte. Para Geertz (1997), a arte faz parte da vida e não há outro meio de interpretá-la senão dentro do fluxo das próprias sociedades. A partir do que propõe Geertz (1997), o cinema se torna um discurso social, passível de interpretação. Se a expressão artística está intimamente pautada na cultura da qual faz parte, a arte é resultado do relacionamento do sujeito com o contexto em que se encontra. $\mathrm{O}$ cinema pode elucidar diferentes perspectivas no que diz respeito às representações, memórias, tempos, espaços, sentimentos, olhares, convergências entre realidade e arte, elementos estéticos e simbólicos. O cinema se torna um meio para o registro do mito e para a mitificação de representações (HIKIJI, 2007).

\section{Considerações sobre representação, juventude e ditadura}

O ano de 1968 é uma referência na forma como são representados os jovens que viveram nas décadas de 1960 e 1970 em diversos lugares do mundo. $\mathrm{O}$ ano se tornou um marco quando se evoca esse passado, quando comumente se faz referência às diversas revoluções, mudanças e guerras que ocorreram no período em vários países, como Alemanha, Polônia, França, China e também na América Latina. Mesmo que os países sejam muito diversos em seus componentes políticos, possuem como representação comum a participação da categoria juvenil, que como pontua Guita Grin Debert (2010: 51), só pode ser compreendida como um produto do contexto do pós-guerra. Grande parte destas representações ganhou espaço nas narrativas formuladas posteriormente em diversos meios de comunicação e arte e, assim, começaram a compor o imaginário social sobre esses anos.

No Brasil, quando se pensa na construção do passado nacional desse período, os jovens também são evocados pelas mais variadas narrativas que foram construídas nos anos pós-ditatoriais, quando foram formulados no

\footnotetext{
${ }^{10}$ A definição clássica do mito pode ser compreendida como uma narração fantástica sobre as origens do mundo, construída usando simultaneamente a imaginação e a memória (García et al. 2009). O mito é um tema muito importante para os estudos antropológicos, no sentido de ser essencial para compreensão do homem e da mulher e de suas relações sociais. Para Rollo May (1998), os mitos são as estruturas que nos permitem dar sentido ao mundo e se utilizam socialmente para paliar a busca de respostas sobre nossa identidade. Leszek Kolakowski (2007) fala sobre a importância do mito na vida social, como garantia de vínculos e de integração no processo de organização da consciência individual (e também coletiva). Além desses autores, o mito e a sua importância na construção do individual e do coletivo nas culturas humanas é tema de diversos outros estudos, como dos autores: Manfred Frank, Claude LévyStrauss, Paul Ricouer, Lluís Duch, Gilbert Durand, Jean-Jacques Wunenburger, Joseph Campbell e Mircea Eliade.
} 
presente formas de entender esse passado. Grande parte das representações sobre o período aponta que a participação dos jovens nas manifestações contra a ditadura ocorreu principalmente através dos movimentos estudantis nas instituições secundaristas e universitárias de todo o Brasil e/ou a partir do contato com movimentos contrários à ditadura. Existem diferentes visões sobre a eficiência desta luta jovem ${ }^{11}$, onde muitos foram torturados, exilados ou estão desaparecidos, porém, há hoje algumas ideias preconcebidas sobre quem eles foram. Contudo, é importante pontuar algumas questões sobre o movimento jovem e estudantil do período e também sobre o conceito de juventude.

Para Daniel Filho (2008), os estudantes nem sempre desempenharam este papel questionador, reformista ou revolucionário no Brasil ou em qualquer lugar do mundo. Ele acredita que essa característica de uma parcela da juventude foi determinada pelo contexto e por certas mudanças sociais, acreditando que estas representações são algo recente, que se desenvolveu após os anos 1960. Além disso, vale ressaltar que a juventude universitária do país dos anos 1960 e 1970 era a minoria e existiam no país entre 120 e 150 mil estudantes (Dirceu, 2008) para uma população de cerca de 80 milhões de pessoas. Segundo dados divulgados em 2011 pelo INEP'2, atualmente, o país possui 6,3 milhões de estudantes em cursos de graduação e 173 mil na pósgraduação, com uma população aproximada de 190 milhões. Porém, mesmo se tratando de uma parcela pequena da população brasileira, a juventude estudantil se tornou o símbolo da caracterização social dos jovens do período, sendo a principal referência nas representações da juventude das décadas de 1960 e 1970.

Esta generalização que há em torno dos jovens do período não é um caso isolado. Atualmente, também pode ser percebida no modo como as sociedades compreendem esta etapa da vida, em que foi construído o mito da juventude homogênea, que como acredita Cecilia Braslavsky (1986), consiste em identificar a todos os jovens como sendo alguns deles. Homogenizar busca simplificar e categorizar os indivíduos. Esta questão me leva a questionar, então, sobre o conceito de juventude. Primeiro, o que é ser jovem? Segundo, é possível falar em apenas uma juventude? Seguindo as sugestões de José Machado Pais (2003), a juventude é percebida como uma categoria construída social e culturalmente. Em nossa sociedade, é possível defini-la como uma "fase da vida", em que é entendida como um grupo de pessoas determinado pela idade ou também pelo momento social em que se encontra, identificado geralmente por ser intermediário entre a infância e a vida adulta, considerada como um momento em que se assumem responsabilidades, mas que são norteadas pelas mais diferentes trajetórias. Porém, como elucida Pais (2003: 32), "histórica e socialmente, a juventude tem sido encarada por uma certa instabilidade associada a determinados problemas sociais".

A partir destes planteamentos, é possível compreender que os jovens são tratados de forma uniforme, em que são retratados dentro de certas categorias ${ }^{13}$.

\footnotetext{
${ }^{11}$ Como demonstra Abramo (1997: 31) enquanto diversos movimentos e civis viam na luta jovem uma possibilidade de renovação, diversos setores que também eram contra a ditadura, como os partidos comunistas e organizações sindicais tradicionais, "interpretavam tais manifestações juvenis como ações pequeno-burguesas inconsequentes quando não ameaçadoras de um processo mais sério e eficaz de negociações para transformações graduais”, além de serem vistos por civis e políticos como responsáveis por acabar com a ordem social.

${ }^{12}$ Instituto Nacional de Estudos e Pesquisas Educacionais Anísio Teixeira.

${ }^{13}$ Cecilia Braslavsky (1986), em seu estudo sobre a juventude argentina, identificou três mitos que são muito utilizados nas representações usuais sobre os jovens. Em resumo: 1) o mito da juventude dourada: relacionado com o ideal de jovem, veiculado à uma imagem de jovialidade e beleza; 2) o mito da juventude cinza: relacionados com problemas e
} 
São enfatizadas representações de senso comum, em que a juventude se torna de interesse de meios de comunicação, governantes e, também, de estudos antropológicos e sociológicos, principalmente no que diz respeito a rupturas sociais. Pais (2003) ainda pontua que a definição da cultura juvenil é como qualquer mito, uma construção que existe mais como representação social do que como realidade. Assim, sigo a sugestão de Campos (2010), que para determinar o que é ser jovem não se deve partir apenas do critério etário, da mesma maneira que se trata de uma categoria ampla, que não pode ser visualizada de forma homogênea, não sendo possível falar em apenas uma juventude. Por este motivo, a categoria é pensada no plural: juventudes, que se dispersam pelo espaço geográfico e social e enfrentam problemas e possibilidades muito distintas e, desta forma, assumem configurações peculiares.

Seguindo Debert (2010), o modo com que a juventude é compreendida hoje, inclusive quando se trata da representação e do imaginário construído sobre os jovens do passado, está relacionado com as mudanças na forma atual de compreender as diferentes categorias etárias, as relações geracionais e o envelhecimento. É possível perceber o alargamento da juventude, que é transformada em um valor, e que pode ser alcançada por todos, a depender das formas de consumo e dos estilos de vida. A autora demonstra que passamos por uma dissolução da vida adulta como experiência de maturidade, no qual a juventude e a velhice perdem conexão com uma faixa etária específica e passam a ser relacionados com os padrões e condutas sociais, influenciados pela sociedade do consumo - e sua propaganda - e pelas possibilidades econômicas, transformação que amplia ainda mais o híbrido e complexo conceito de juventudes.

Como dito anteriormente, um dos modos mais usuais de representar a juventude é a partir da ideia de rebeldia, tensões e problemas sociais, que pode ser interpretado de diferentes formas. No caso dos jovens, em suas multiplas faixas etárias, que viveram na ditadura, grande parte aparece dentro dessa perspectiva. Porém, para Abramo (1997), foi a partir da ditadura que a juventude brasileira se mostrou como uma categoria que podia realizar uma "transformação profunda" para grande parte da sociedade e começou a chamar mais atenção de governantes, pesquisadores, etc. A associação desta juventude com rupturas sociais ou com o perfil questionador e corajoso também foi responsável por, a partir dos anos 1960, levar os jovens a uma categoria social representativa politicamente e, desta forma, tornar-se tema de interesse de diferentes estudos das ciências sociais e de diversas representações e releituras sobre o período.

Nesse sentido, compreendo que, ao lado da grande mídia e dos trabalhos acadêmicos $^{14}$, os produtos culturais se tornaram importantes mecanismos de representação da juventude. O audiovisual, como o cinema e a televisão, apresenta um modo de tematizar os jovens, além de ser uma forma de influenciar também as suas opiniões e os seus modos de vida. A crescente participação da arte, da mídia, da internet e dos meios de comunicação na vida

tensões sociais; 3) o mito da juventude branca: relacionado à personagens maravilhosos, heróis, capazes de salvar o mundo e de fazer aquilo que seus pais não puderam.

${ }^{14}$ Desde a década de 1960, muitos trabalhos foram realizados com o objetivo de discutir a cultura juvenil e os diferentes papéis que os jovens começaram a desempenhar em todo o mundo. Desse período, apenas a caráter de exemplo, cito os livros Outsiders - Estudo da sociologia do desvio (2008), escrito no início dos anos 1960 por Howard Becker, que trouxe uma mudança na forma como a sociologia tratava o tema, e Resistance through rituals (1975), organizado por Stuart Hall e Jefferson Tony, que traz alguns textos sobre as subculturas jovens inglesas do pós-guerra. 
das pessoas é uma das grandes responsáveis por desenvolver a ideia que a sociedade tem acerca da identidade jovem dos anos 1960 e 1970 nos dias de hoje, que também influencia a percepção sobre os jovens atuais. Os filmes são capazes de criar diálogos com a memória da nação e produzir e reformular os mitos sobre a juventude, do passado e do presente. Desta forma, todas as representações sobre os jovens, tanto nas artes como nas pesquisas - que optam por apresentar determinado ponto de vista - são responsáveis por influenciar a forma como a sociedade os enxergam e como os próprios jovens se veem. Em resumo, a maneira como a sociedade imagina a sua juventude também é refletida no cinema, que influencia e é mutuamente influenciado pelos discursos que são produzidos sobre os jovens. As representações que são construídas sobre determinados aspectos sociais, como memórias ou agentes, fazem parte de um processo maior de construção de identidade, em que se busca dar formas para questões que são comuns a todos. Todas as representações estão atreladas às diversas tensões que permeiam a formulação e a apropriação da memória.

\section{Entre a rebeldia e a ingenuidade: os jovens de ontem no cinema de hoje}

A partir da antropologia, uma das possíveis escolhas para a análise de uma obra cinematográfica é a etnografia. A etnografia fílmica permite ao pesquisador experimentar e ampliar as possibilidades de análise do filme e de seu universo. Parto da ideia de que investigar uma obra cinematográfica, desde uma perspectiva antropológica, significa interpretá-la densamente. Se entendo o filme como linguagem, onde há significados literais denotados e significados simbólicos conotados, proponho que a etnografia leve em consideração todo o contexto de produção da obra para que possam ser decifrados os discursos produzidos pela narrativa, o que também solicita que seja compreendida a relação entre autor-obra-circuito-espectador ${ }^{15}$.

Para isso, a medologia da pesquisa contou com três etapas principais: 1) Coleta de dados: que inclui pesquisas relativas aos autores dos filmes e livros e também à produção e circulação dos longas-metragens, realizada a partir de buscas na internet, relatórios oficiais do mercado cinematográfico brasileiro, entrevista ${ }^{16}$ e análise de entrevistas realizadas para jornais e páginas de internet. 2) Análise textual: que contou com as análises textuais, que começaram com a observação e interpretação de dois diferentes textos sobre uma mesma "memória". Primeiro aconteceu a leitura dos livros em que os filmes foram inspirados, seguido dos roteiros dos filmes. A leitura dos roteiros, depois a comparação com livros e filmes, possibilitou-me perceber diversas sugestões que neles continham, das intenções do autor, que podem não ficar claras na imagem. 3) Análise fílmica: que diferente da análise inicial dos livros e dos roteiros, o texto fílmico solicitou que fossem interpretados tridimensionalmente imagem, áudio e texto. Em primeiro lugar, para realizar a etnografia das obras

\footnotetext{
${ }^{15}$ Com "a morte do autor", Barthes anunciou o nascimento do leitor. Como Stam (2003) pontua, não há como levar a ideia para o cinema da mesma forma, pensando no nascimento do espectador. O cinema já nasceu levando em conta a reação e o contato com o outro. A espectatorialidade sempre esteve no cerne do ideal cinematográfico, porém, nos últimos anos, o espectador e sua relação com o filme passaram a ser encarados de outra forma, em que se compreende a importância de quem assiste para a criação da narrativa fílmica.

${ }^{16}$ Procurei entrevistar os dois diretores, porém só consegui contato com Helvécio Ratton. Tentei algumas vezes marcar com o diretor Bruno Barreto, que informou, através de sua secretária, estar ocupado com a pós-produção de um longametragem, porém, a secretária sugeriu que eu enviasse as perguntas por e-mail, que ele responderia quando tivesse um tempo, fato que não ocorreu.
} 
organizei as análises a partir das áreas principais do cinema: direção de cena, fotografia, arte, som e montagem/edição. O objetivo foi perceber como cada área auxiliou o autor da obra, neste caso o diretor de cena, a contar a história pretendida, como por exemplo, percebendo quais foram os recursos utilizados na montagem. Tratei de observar nas referidas obras como os tons, as músicas, os diálogos buscam traçar uma identidade aos jovens e, assim, constatar os possíveis imaginários e influências que esta juventude exerce hoje e as diferentes memórias que são formuladas a partir dos filmes, levando em consideração as construções de diferentes tempos e espaços sobre esse passado e a forma como ele é ressignificado.

O filme $O$ que é isso, companheiro? narra o sequestro do embaixador norte-americano Charles Burke Elbrick pelo Movimento Revolucionário Oito de Outubro - MR8, com participação da Aliança Libertadora Nacional - ALN, no Rio de Janeiro, em setembro de 1969. O filme tem direção de Bruno Barreto, que não participou de nenhum movimento contrário à ditadura, mas tem algumas recordações sobre o período. Diferente do caso de Batismo de Sangue, que retrata o envolvimento de frades dominicanos com a ALN, em 1968. O diretor Helvécio Ratton participou de um grupo revolucionário, foi preso três vezes e exilado do país. As trajetórias dos diretores são fatores importantes para entender o modo como as narrativas fílmicas foram conduzidas e quais são as relações existentes com a memória do período.

Ambos os filmes começam com letreiros para contextualizar as histórias que se iniciam, recurso utilizado durante outros momentos dos longas. O uso do texto deixa visível a pretensão histórica dos autores das obras, isto é, de fazer do filme um "documento". Com uma fotografia escura, com tons cinzas, a primeira cena de Batismo de Sangue traz o final do filme: o suicídio de frei Tito, durante o seu exílio na França. Temos contato com os sentimentos de medo e tristeza e as próximas cenas vão tentar explicar o que levou o frade a tirar a própria vida. $\mathrm{Na}$ próxima sequência, em outro momento muito mais claro, vemos novamente o personagem, mas com outro ânimo, cheio de esperanças. Porém, a relação do espectador com o filme vai partir da certeza da imagem anterior, sabe-se que o final não é feliz. Já o começo de $O$ que é isso, companheiro? traz três personagens da história, entre eles o protagonista, na passeata dos cem mil, uma manifestação que ocorreu no Rio de Janeiro contra a ditadura. As imagens, em preto e branco, são misturadas à cenas filmadas no dia real da passeata, e com o coro "o povo unido jamais será vencido", traz - novamente - um sentimento de esperança. Porém, no decorrer do filme a esperança também vai sendo desconstruída. No final, percebemos que ambos os filmes assumem que os jovens foram derrotados pela força da repressão, mas o significado e a importância da luta que eles tiveram é o que está em tensão desde o primeiro momento das obras.

Os dois filmes apresentam inicialmente jovens descontentes com os rumos políticos do país, que se aproximaram da luta armada com o objetivo de mudar e derrubar o governo militar. Em $O$ que é isso, companheiro?, um grupo de jovens entra para uma organização clandestina e em Batismo de Sangue, um grupo de frades, que também são universitários, se unem a uma organização com o objetivo de lutar contra a repressão. Por mais que os frades não pegassem em armas, os dois grupos possuem objetivos semelhantes. A caracterização social dos jovens também se repete: são todos brancos, de classe média, estudados e críticos. Além disso, fazem parte de uma pequena parcela da 
juventude, tendo o isolamento, o sonho e a ingenuidade também como características comuns. Entretanto, novamente o significado das representações dos jovens é antagônico.

Em Batismo, a juventude retratada é heróica e simboliza o bem que luta contra o mal. Nesse caso, a ligação dos jovens com a religião, e todo o poder simbólico que a figura do religioso possui na sociedade, auxilia ainda mais nesta distinção maniqueísta que propõe a obra de Ratton, em que didaticamente, de um lado esta a pureza dos frades e do outro o perigo dos militares. Já o filme de Barreto, entre as obras brasileiras que retratam o tema, é o que mais se distância no modo de representar os jovens. Diferente da ideia de uma juventude heróica, que se sacrificou pelo país, o filme busca apresentá-la a partir do viés do "problema social", destacando mais o seu isolamento, suas fraquezas e ingenuidades.

Em $O$ que é isso, companheiro?, o grupo que vai realizar o sequestro do embaixador, em troca da leitura de um manifesto em rede nacional e da libertação de 15 presos políticos, é composto por Paulo, Maria, Marcão, Julio e Renné, que recebem um "reforço" de São Paulo, da ALN, de dois guerrilheiros experientes, Jonas e Toledo, que podem ser interpretados como uma força "adulta" tipificada, em oposição aos jovens também tipificados. Diferente do modo como o "bem" e o "mal" são trabalhados na obra de Ratton, e em grande parte dos filmes do gênero, o "bem" e o "mal" existem dentro do próprio grupo guerrilheiro, em que de um lado está Paulo, que por mais que não tenha jeito com as armas, é erudito, crítico, inteligente e mais lúcido que os demais e, do outro, está Jonas, que veio comandar a operação e é representado como uma pessoa fria, capaz de matar os próprios companheiros, caso seja desobedecido, e que acaba por criar conflitos e disputas dentro do grupo, questões que são bastante exploradas no filme durante os quatro dias em que eles ficam com o embaixador sequestrado.

Há três grandes questões que rondam a história de $O$ que é isso, companheiro? e o afasta ainda mais das demais obras sobre o período. A primeira é que ele é centrado no embaixador norte-americano, representado como um homem gentil e carinhoso, em que foi construído um personagem com o estereótipo de um adulto "normal" e desejável, parte de uma família também "normal". Sobre isso, vale ressaltar que Barreto morava nos Estados Unidos, onde realizou alguns trabalhos, quando foi ai Brasil dirigir o filme, o que ajuda a explicar o viés dado à obra, que contem diversas referências para o público do exterior. Também é importante lembrar que o filme fez uma boa carreira nos EUA e concorreu ao Oscar de Melhor Filme Estrangeiro. O segundo ponto é a humanização do torturador, que em alguns momentos do filme tem crises de consciência. E, o terceiro, é a maneira como os jovens foram representados, que se inicia com a escolha dos atores. O elenco é formado por diversos atores conhecidos no Brasil, que atuam em produções televisivas para a Rede Globo, como Pedro Cardoso (Paulo), Fernanda Torres (Maria), Cláudia Abreu (Renée) e Luiz Fernando Guimarães (Marcão). Contudo, deve-se notar que muitos dos atores são associados à programas humorísticos ou novelas. Essa questão não desqualifica as atuações, porém, o público faz parte de um universo de discursos e linguagens maior e acaba identificando os atores pelos papéis que estão mais acostumados a ver. $\mathrm{O}$ espectador está habituado a assistir Fernanda Torres, Luiz Fernando Guimarães e Pedro Cardoso, por exemplo, atuando juntos em séries de comédia. De alguma maneira, a escolha dos atores dá esse tom aos 
personagens do filme. Além disso, como o enfoque da obra é em tramas pessoais, percebo que o embaixador e o torturador são personagens tratados de modo mais denso que os guerrilheiros.

Em Batismo de Sangue, a escolha dos atores também é importante e traz uma forte carga simbólica para a obra. Daniel de Oliveira (frei Betto) e, principalmente, Caio Blat (frei Tito), são referências no cinema brasileiro na interpretação de jovens e as diferentes relações com a cultura nacional. Oliveira, por exemplo, viveu no cinema a história do músico Cazuza e Caio Blat tem em seu currículo uma série de personagens jovens, geralmente vinculados com problemas sociais, como em Cama de Gato (2002), Carandiru (2003) e Proibido Proibir (2007).

No filme de Ratton, é a partir de ideais cristãos, que os personagens que estão no centro da ação do filme, os frades Tito, Betto, Osvaldo, Fernando e Ivo, passam a apoiar o grupo guerrilheiro ALN, de Carlos Marighella. Os frades se baseiam na bíblia e em filósofos, como Santo Thomas de Aquino, para demonstrar a importância da participação da igreja na ação contra a ditadura. A relação entre eles é descoberta pelo Departamento de Ordem Política e Social DOPS, o que os leva à prisão, quando Tito, Osvaldo e Fernando são brutalmente torturados pela equipe do delegado Fleury. Para desenvolver os personagens, Ratton optou por uma construção maniqueísta, com o objetivo de não deixar dúvidas, e para auxiliar nessa percepção, traz a tortura a qual os frades foram submetidos para o centro da história, com alta dose de realismo. As cenas "incomodam" pela força da violência, representada tanto visualmente como pelo som. Os gritos dos torturadores e o som das torturas e dos golpes são mais altos e tentam fazer com que os espectadores entrem na cena e sintam um pouco do que eles sentiram. A câmera também participa da ação, em alguns momentos como se fosse uma parte do corpo dos personagens, enquanto os frades levam choques, a câmera treme seguindo os movimentos de seus corpos. Os torturadores se mostram frios e chegam a falar em outros assuntos, como uma viagem a Ilha Bela ou o tempo em São Paulo, ou ainda tomam café durante a tortura dos personagens, questão que acontece também em $O$ que é isso, companheiro?, mas de um modo muito mais sutil. Enquanto no filme de Barreto, os guerrilheiros são transformados em caricaturas, na obra de Ratton isso acontece um pouco com os torturadores, o que pode ser compreensível, já que se trata de uma representação sobre a tortura.

Além disso, a universidade é um dos cenários de Batismo de Sangue, onde há grandes questões para apontar no que se refere à representação da juventude do período, primeiro porque a juventude universitária, como apontei no subtítulo anterior, é a mais evocada quando se busca representar os jovens da época. Então, mesmo se tratando de uma minoria possui uma importância, que também é simbólica, muito grande. É neste ambiente universitário que ocorrem reuniões e há diversos processos de resistência à ditadura. Outra questão muito destacada na obra de Ratton, que aparece com menos ênfase em $O$ que é isso, companheiro?, é a relação com o Brasil, que é entendido como um tema bastante importante para compreender a juventude e, especificamente, o caso de Tito, que estava preso com os outros frades, mas é enviado para o exílio no exterior. As memórias em relação ao país e o sentimento nacional são questões muito trabalhadas no filme. Dessa forma, a obra afirma o desejo de reparação, por alguém que deu a vida pelo país e não tem esse reconhecimento. 
No filme, Ratton optou em representar um núcleo especifico, mas composto pelos diversos signos do que era ser jovem no período. Mesmo falando claramente de cristãos, o filme representa jovens. Como mencionado, até por ser uma forma de identificação com público, a relação com a igreja e a fé está presente em toda a obra, mas também o gosto pela música, pela literatura, a vida na universidade e outros diversos assuntos que envolvem o universo juvenil. Além da juventude dominicana e do movimento estudantil, também há referências aos jovens que participaram ativamente da luta armada e àqueles que não fizeram parte deste processo de luta.

Em relação à representação da juventude, o mesmo acontece com o filme de Barreto, que também utiliza símbolos já estabelecidos como pertencentes à memória nacional sobre o período, que persistem na forma como se compartilha a nação até hoje. Os dias que os jovens ficam com o embaixador na casa são divididos entre cuidar do estadunidense e outras atividades normais da idade, como fazer exercícios, ler gibis ou revistas, como uma sobre o Woodstock, outra referência deste passado, lida por Renée. Também, a construção da imagem dos personagens levou em consideração as representações mais usuais sobre os anos 1960 e 1970. Como por exemplo, as roupas, em que as mulheres do grupo usam minissaias e jeans em diversas cenas. A relação com a arte, também é evocada, como pela música da época. Nesse caso, Chico Buarque é um personagem muito comum na relação entre cultura e política brasileira, também presente em Batismo de Sangue.

No final de $O$ que é isso, companheiro?, percebemos que entre a formação e a ação do grupo guerrilheiro, o filme representa jovens que iniciam e terminam a trama como sonhadores. A partir da leitura do filme, suas ações parecem inconsequentes, despreparadas e ingênuas. Aos poucos, o grupo parece que não estava preparado para a ação e, no final, todos são presos e também somos avisados por uma narração em off, que Jonas e Toledo foram mortos. Já o final de Batismo de Sangue traz novamente a esperança com a liberdade dos outros frades que continuavam presos, mas volta para a cena do suicídio. Assim, entre 1968 e 1974, tempo em que se desloca a narrativa do filme, a obra apresenta uma juventude que, aos poucos, vai perdendo a força e se tornando vítima da violência da repressão do Estado. Aqui, podemos evocar novamente a questão da nação. O filme apresenta jovens que se arriscam por amor à Pátria, mas de alguma forma em vão, porque não são percebidos pela sociedade, nem lembrados, e é esta compreensão que o filme também quer alterar, discutindo o tema.

Para finalizar, lembro da importância da montagem para os filmes, fator que ajuda a estabelecer a continuidade do tempo ao longo das narrativas, que se deslocam por um grande período, principalmente no filme de Ratton, que além de trabalhar na perspectiva de anos, utiliza muito o recurso de flashbacks, quando são sobrepostos no presente diferentes tempos do passado. Também, ambos utilizam a fotografia e a iluminação para criarem relação com o tempo. Ainda há a preocupação em evidenciar locais que existem, ambientalizando os espaços, para criar identificação com o público. 


\section{Considerações finais}

A presente participação da juventude em narrativas de filmes sobre a ditadura está relacionada à maneira como foram reformuladas nos anos pósditatoriais a atuação desta categoria - muitas vezes por aqueles que eram jovens no período, como o caso dos autores do filmes analisados e dos livros em que foram baseados - que se faz presente em grande parte das releituras que tratam desses anos, em diversos formatos. Como dito, isso também está relacionado com as representações que trazem as juventudes como protagonistas em diversas transformações culturais e sociais em outros lugares do mundo. No âmbito da tensão pelas representações sociais, os discursos hegemônicos buscam apropriar-se das identidades, sugerindo como os diferentes grupos devem reconhecer-se, além de classificar (e muitas vezes inventar) o outro e, dessa forma, a percepção sobre este.

Após a análise dos filmes $O$ que é isso, companheiro? e Batismo de Sangue, percebi que há uma homogeneização dos jovens, neste caso, àqueles que participavam dos movimentos contrários ao regime. Mesmo que é destacado, em ambas as obras, o isolamento desses grupos e a postura de outros agentes sociais da mesma faixa etária, que possuem relações distintas com a situação política do Brasil, a juventude protagonista das obras é representada a partir de características físicas, econômicas e culturais comuns, que já estão no imaginário social e coletivo sobre o que foi ser jovem naquele período. $\mathrm{O}$ fato desses jovens terem sido "isolados", na realidade, favorece seu enaltecimento, já que entram na categoria da juventude politizada, em que é possível contrastar e mitificar seus atos. Dessa form, sua luta, que pode ser interpretada e representada de forma positiva ou negativa, ganha mais espaço. Diferente do caso de $O$ que é isso, companheiro?, em grande parte dos filmes brasileiros que tratam do tema, assim como em Batismo de Sangue, é priorizado os aspectos positivos, que se tornam uma tipificação idealizada do jovem do período, que reflete na maneira como a sociedade entende o tipo ideal de jovem brasileiro e traz em suas entrelinhas importantes reflexões sobre como se entende o jovem hoje e, também, sua relação com a política.

Os filmes destacam símbolos comuns, às vezes com significados diferentes, que já fazem parte da memória social sobre o período, reafirmando-os como parte do passado. O objetivo é criar uma identificação com o público, mesmo entre aqueles que não vivenciaram esses anos. Assim, as obras se aproximam também nas referências sobre as formas como a sociedade compartilha o imaginário sobre o jovem do período, em que são acionadas, além de questões culturais e estéticas, a ligação entre os movimentos contrários à ditadura com a universidade e a leitura de determinados filósofos ou revolucionários.

A relação com a nação também aparece nas duas obras. A nação é colocada como a principal motivação dos personagens para entrar na luta contra a ditadura. Nesse sentido, o envolvimento não parte apenas de uma intenção e de um desejo pessoal, mas do objetivo de alcançar um bem maior. Parte-se da ideia de que os jovens se envolviam na luta para buscar a mudança e assim ajudar toda a sociedade brasileira. Era o amor ao Brasil que os impulsionava, por mais que este sentimento não tenha uma forma única. Em cada filme são diferentes os modos pelos quais os jovens se relacionam com a pátria.

Entretanto, o que mais me interessa nos filmes é a diferença, que mesmo em se tratando do mesmo tempo narrativo e das semelhanças com que se 
apropriam dos signos e símbolos, é muito visível entre as obras. A diferença existente destaca os distintos fluxos em relação ao entendimento e à memória sobre o período. Sobre isso, ressalto a relação que os dois autores têm com a noção de memória, muito presente em ambos os filmes, porém, de maneiras distintas. Em Batismo de Sangue, noto que a preocupação com a memória é muito maior, principalmente pela relação com as lembranças do próprio Ratton. Já Barreto não demonstra muito envolvimento pessoal com as memórias sobre o tema que aborda. As histórias de vida dos diretores são questões determinantes para indicar as escolhas no tratamento dado aos filmes. Batismo de Sangue busca se aproximar mais do que é narrado no livro. Porém, destaca determinados pontos de vista e os maximiza. Já $O$ que é isso, companheiro? utiliza o livro como base para a história, mas cria uma nova interpretação em cima das questões narradas por Gabeira.

Os filmes deixam claro que a parcela de jovens que lutou contra o regime é pequena, com características comuns, mas significados diferentes. Se de um lado eles são bondosos, politizados e exemplos de um ideal de juventude, do outros eles se aproximam muito mais dos discursos que agregam à juventude a ideia de relação com "problemas sociais", sendo destacadas as rebeldias de uma fase da vida, que devido ingenuidades, foram responsáveis por envolvê-los em problemas e por levá-los a incluir também outras pessoas, como o caso do embaixador. Entretanto, vale ressaltar, que a postura dos jovens do passado é muito acionada em diversos discursos sociais que visam representar a juventude atual. O cinema é apenas mais um lugar onde estes discursos também se tensionam, que influencia e é influenciado pela forma como a nação compreende esta fase de vida e, também, como os jovens se veem dentro da sociedade.

O mito existente sobre a participação juvenil na luta contra a ditadura é reafirmado em Batismo de Sangue e desconstruído em $O$ que é isso, companheiro?. Enquanto no primeiro, os jovens são tomados a partir da ideia de que eles são heróis, no segundo eles apenas sonhavam em ser. Ambos os filmes apontam que os jovens perderam as batalhas, mas a importância da participação nesta luta é o que se contrasta e se tensiona nos filmes, que estão à procura de diferentes interpretações.

\section{Referências}

ABRAMO, Helena. Considerações sobre a tematização social da juventude no Brasil. Revista Brasileira de Educação, 6, p. 25-36, 1997.

BARRETO, Bruno. "Para Barreto, filme não é para torturados". Entrevista realizada por Luis Caversan. Folha de S. Paulo, 1997. Disponível em: http://acervo.folha.com.br/fsp/1997/05/o7/21/ Acesso em dezembro de 2012.

BARRETO, Bruno; CARNEIRO, Geraldo. Roteiro de $O$ que é isso, companheiro?, São Paulo: Cinemateca Brasileira, 1988.

BARTHES, Roland. O rumor da língua. São Paulo, Martins Fontes, 2004. . Mitologias. Rio de Janeiro, DIFEL, 2009.

BETTO, Frei. Batismo de sangue. São Paulo, Círculo do livro, 1982. 
BRASLASKY, Cecilia. La juventud argentina: informe de situación. Centro Editor: Buenos Aires, 1986.

CAMPOS, Ricardo. Juventude e visualidade no mundo contemporâneo: uma reflexão em torno da imagem nas culturas juvenis. Sociologia, Problemas e Práticas, 63, p. 113-137, 2010.

DE NORONHA, Danielle Parfentieff. Cinema, memória e ditadura civilmilitar: representações sobre as juventudes em $O$ que é isso, companheiro? e Batismo de Sangue. Dissertação de mestrado. São Cristóvão: Universidade Federal de Sergipe, 2013.

DEBERT, Guita Grin. A dissolução da vida adulta e a juventude como valor. Horizontes Antropológicos, 34, p. 49-70, 2010.

DIRCEU, José. O movimento estudantil em São Paulo. In: M. A. Garcia, M.A. Vieira (Eds.), Rebeldes e contestadores - 1968: Brasil, França e Alemanha. São Paulo, Perseu Abramo, 2008.

DUCH, Lluis; CHILLON, Albert, Un ser de mediaciones: Antropología de la comunicación, Vol 1. Barcelona, Herder, 2012.

FILHO, Daniel. "1968, o curto ano de todos os desejos". In: M. A. Garcia, M.A. Vieira (Eds.), Rebeldes e contestadores - 1968: Brasil, França e Alemanha. São Paulo, Perseu Abramo, 2008.

GABEIRA, Fernando. O que é isso, companheiro? Rio de Janeiro, Codecri, 1981.

GARCIA, José; CANUL, Jesús; LÓPES, Fredy. El mito del poder en la sociedad contemporánea. Uni-pluri/versidad, 9 (3), p. 1-14, 2009.

GEERTZ, Clifford. O saber local. Petrópolis, RJ Vozes, 1997.

HALBWACHS, Maurice. A memória coletiva. São Paulo, Vértice, Editora Revista dos Tribunais. 1990.

HIKIJI, Rose S. Gitirana. "O cinema à luz da antropologia e vice-versa". In: ZANINI, Maria Catarina Chitolina (Org.) Por que "raça"? Reflexões sobre "questão racial” no cinema e na antropologia. Santa Maria: Ed. UFSM, 2007.

INEP. Censo da educação superior 2010. Distrito Federal: INEP, 2011. Disponível em: http://www.ufla.br/ascom/wp-content/uploads/2011/11/7.11censo-educa\%C3\%A7\%C3\%A30-superior.pdf Acesso em maio de 2015.

KOLAKOWSKI, Leszek. La presencia del mito. Madrid, Amorrortu, 2007.

MAY, Rollo. La necesidad del mito La influencia de los modelos culturales en el mundo contemporánea. Barcelona, Paidos, 1998.

PAIS, José Machado. Culturas juvenis. Lisboa: Imprensa nacional-Casa da moeda, 2003.

RATTON, Helvécio; PARATTA, Dani. Batismo de Sangue. São Paulo: Imprensa Oficial, 2008.

RATTON, Helvécio. Entrevista concedida à Danielle Parfentieff de Noronha. Aracaju, 2012. 


\section{Referências filmográficas}

Batismo de Sangue. Direção: Helvécio Ratton. Minas Gerais: Quimera Filmes, 2007.

O que é isso, Companheiro? Direção: Bruno Barreto. Rio de Janeiro: Filmes do Equador, 1997. 